\title{
KEANEKARAGAMAN BURUNG DI KAWASAN LAHAN BASAH KOTA BATAM
}

\section{DIVERSITY OF BIRDS AT BATAM WETLAND AREA}

\author{
Fauziah Syamsi \\ Program Studi Pendidikan Pendidikan Biologi, Fakultas Keguruan dan Ilmu Pendidikan, \\ Universitas Riau Kepulauan, Indonesia
}

Koresponden: fauziahsyamsi@gmail.com

\begin{abstract}
Abstrak
Penelitian ini bertujuan untuk mengidentifikasi keanekaragaman fauna burung di lahan basah Kota Batam dan mengidentifikasi status lahan basah berdasarkan keanekaragaman fauna burung yang terdapat disana. Penelitian ini dilakukan pada bulan Desember 2016 sampai Januari 2017 di Rempang dan Tg. Piayu, Kota Batam. Penelitian ini menggunakan metode survei dan pengamatan langsung di kawasan hutan mangrove dan sekitarnya. Pengamatan lapangan dilanjutkan analisis rekaman gambar di laboratorium. Setelah dilakukan pengamatan terhadap jenis-jenis burung di lokasi penelitian ditemukan 327 individu yang terdiri dari 7 Ordo, 12 Famili dan 23 jenis. Famili dengan jumlah individu terbanyak adalah Ardeidae yaitu sebanyak 207 individu yang terdiri dari 5 spesies. 11 spesies burung yang ditemukan di lokasi penelitian merupakan burung yang dilindungi berdasarkan Undang-Undang No. 7 tahun 1999. Tingkat keanekaragaman burung di dua lokasi penelitian tergolong sedang yaitu dengan nilai indeks keanekaragaman (H') burung di Rempang adalah 2,01 dan di Tg Piayu adalah 2,33. Nilai indeks kemerataan spesies ( $\left.\mathrm{J}^{\prime}\right)$ di Rempang tergolong sedang, yaitu 0,66 dan di Tg. Piayu tergolong tinggi yaitu 0,82 .
\end{abstract}

Kata Kunci: Fauna burung, Keanekaragaman, Lahan basah, Hutan mangrove

\begin{abstract}
This study aims to identify the diversity of bird in the Batam wetlands and identify wetland status based on the diversity of bird. This research was conducted in December 2016 until January 2017 in Rempang and Tg. Piayu, Batam. This research uses survey method and direct observation in mangrove forest area and its surroundings. Field observation followed by analysis of image recording in the laboratory. After observation of bird species in the study site found 327 individuals consisting of 7 Orders, 12 families and 23 species. Family with the largest number of individuals is Ardeidae that is as many as 207 individuals consisting of 5 species. 11 species of birds found in the study sites were birds protected under Undang-Undang No. 7 in 1999. The level of diversity of birds in two research sites is moderate with the value of the diversity index $\left(H^{\prime}\right)$ of birds in Rempang is 2.01 and in Tg Piayu is 2.33. The values of the evenness index of species $\left(\mathrm{J}^{\prime}\right)$ in Rempang are moderate, is 0.66 and in Tg. Piayu relatively high is 0.82 .
\end{abstract}

Keywords: Birds, Diversity, Wetland, Mangrove forest 


\section{PENDAHULUAN}

Burung adalah satwa yang sangat penting dalam sebuah ekosistem. Salah satu fungsi burung dalam ekosistem adalah sebagai indikator untuk menilai biodiversitas dalam suatu wilayah, karena mereka dapat menempati habitat yang luas dan juga mendekati puncak dari rantai makanan (Djuwantono et al., 2013). Jika burung dihilangkan dari suatu ikatan mata rantai pakan, maka serangga-serangga yang menjadi sumber pakan burung akan berkembang biak tanpa terkendali dan menjadi hama, yang pada akhirnya akan terjadi ketidakseimbangan dalam suatu mata rantai kehidupan (Wechsler \& Wheeler, 2012).

Selain indikator dalam menilai biodiversitas, burung juga merupakan indikator yang baik bagi perubahan lingkungan (Bibby et al., 2000). Hal tersebut disebabkan karena satwa burung terdapat hampir di seluruh habitat daratan pada permukaan bumi ini dan bersifat sensitif pada kerusakan lingkungan. Pengetahuan taksonomi dan sebaran burung relatif banyak diketahui, dan lebih baik dibandingkan biota yang berukuran besar dan kelas-kelas lainnya. Penggunaan burung sebagai indikator nilai keanekaragaman hayati merupakan satu jalan tengah yang terbaik antara kebutuhan informasi ilmiah yang akurat dengan keterbatasan waktu yang ada bagi aksi konservasi (Indrawan \& Ermayanti, 1997 dalam Primack et al., 1998). Ada beberapa jenis burung yang memiliki kepekaan tertentu terhadap kesehatan lingkungan habitatnya, salah satu diantaranya sebangsa burung raja udang (Sozer et al., 1999).

Kawasan pesisir pantai yang pada umumnya terdiri dari lahan basah berupa hutan mangrove merupakan habitat yang sangat baik bagi burung, terutama burung air maupun burung daratan lainnya. Hutan mangrove digunakan oleh burung sebagai habitat untuk mencari makan, berbiak atau sekedar beristirahat. Habitat mangrove menyediakan ruang yang memadai untuk membuat sarang, terutama karena tersedianya makanan dan bahan pembuat sarang. Hutan mangrove juga menyediakan tenggeran serta sumber makanan yang berlimpah. Hamparan lumpur merupakan habitat yang sangat sesuai untuk mencari mangsa bagi beberapa jenis burung air. Disamping itu, akar mangrove merupakan tempat istirahat yang baik selama air pasang dalam musim pengembaraannya (Howes, et al., 2003).

Luas hutan mangrove di Indonesia dari tahun ke tahun selalu mengalami penurunan. Pada tahun 1982 tercatat seluas 5.209.543 ha. Luasan tersebut menyusut sampai 46,96\% atau tersisa 2.496.158 ha pada tahun 1993. Kondisi ini juga beriringan dengan penurunan kualitas hutan 
mangrove. Hal ini memberikan dampak yang cukup serius bagi fauna yang menggantungkan hidupnya pada ekosistem mangrove, salah satunya adalah burung. Dengan demikian, burung bisa dijadikan sebagai indikator lingkungan pada habitat pesisir, khususnya hutan mangrove (Junardi dan Elfidasari, 2006).

Sebagian besar pengalihfungsian hutan mangrove di Indonesia terkait dengan kegiatan penebangan kayu serta pengembangan daerah menjadi kawasan lain yang memiliki nilai ekonomi jangka pendek, seperti tambak dan kepentingan lainnya berpengaruh terhadap ketersediaan makanan serta perubahan fungsi ekosistem. Hilangnya habitat alami akan menyebabkan hilangnya keanekaragaman makanan yang merupakan pendukung kehidupan mereka (Howes, et al., 2003).

Mengingat pentingnya keberadaan fauna burung dalam sebuah ekosistem serta pentingnya menjaga kelestarian ekosistem mangrove maka penelitian Keanekaragaman Burung di Kawasan Lahan Basah Kota Batam ini perlu dilakukan.

\section{METODOLOGI PENELITIAN}

Penelitian ini menggunakan metode survei dan pengamatan langsung di kawasan hutan mangrove dan sekitarnya. Pengamatan lapangan dilanjutkan analisis rekaman gambar di laboratorium. Penjelajahan jalur pengamatan dilakukan tiga kali dalam waktu yang berbeda sebagai ulangan. Pengamatan lapangan dilakukan dengan menyisir lahan basah dan mengamati burung yang terlihat di kawasan tersebut. Metode sensus burung dilakukan dengan membuat satu seri daftar jenis burung air yang berada/tampak di sepanjang lokasi penyisiran selama waktu pengamatan. Setiap jenis baru dicatat hingga mencapai 10 jenis, lalu dibuat daftar baru lagi. Jenis yang sama tidak boleh dicatat dua kali dalam satu daftar (MacKinnon dkk., 1994). Identifikasi jenis burung air juga dilakukan langsung di lapangan berdasarkan bentuk morfologinya, dengan merujuk Howes dkk. (2003), meliputi: (i) bentuk dan ukuran tubuh, paruh, dan kaki, (ii) warna bulu pada tubuh, paruh, dan kaki, (iii) ciri-ciri khas yang tampak, serta (iv) suara yang dihasilkan. Selain itu juga dilakukan dokumentasi dengan kamera video dan kamera foto untuk kemudian diidentifikasi lebih lanjut di laboratorium. Analisis data yang dilakukan sebagai berikut: 
1. Keanekaragaman spesies

Keanekaragaman spesies pada tiap tipe habitat dianalisa dengan menggunakan indeks Shannon Wiener (H') dengan rumus:

$$
\begin{aligned}
& \mathrm{H}^{\prime}=-\sum p i \ln p i \\
& \text { dimana } \mathrm{Pi}=\mathrm{ni} / \mathrm{N}
\end{aligned}
$$

Dengan: H' = Indeks keanekaragaman Shannon-Wiener

$\mathrm{S} \quad=$ Jumlah spesies

ni $\quad=$ jumlah individu spesies ke $\mathrm{i}$

$\mathrm{N} \quad=$ jumlah total seluruh individu

Kriteria yang digunakan untuk menginterpretasikan keanekaragaman Shannon-Wiener yaitu:

$\mathrm{H}^{\prime}<1$, tingkat keanekaragaman rendah

$\mathrm{H}^{\prime}=1-3$, tingkat keanekargaman tergolong sedang

$\mathrm{H}^{\prime}>3$, tingkat keanekaragaman tinggi

3. Indeks Kemerataan (J')

Tingkat kemerataan (evenness) dihitung dengan menggunakan rumus:

$$
\mathrm{J}^{\prime}=\mathrm{H}^{\prime} / \ln \mathrm{S}
$$

Keterangan: J' : Indeks kemerataan

$\mathrm{H}^{\prime}$ : Indeks keanekaragaman Shanon-Wiener

$\mathrm{S}:$ Jumlah spesies

Kategori kemerataan spesies burung yang digunakan yaitu:

- rendah untuk nilai indeks kemerataan 0,10 sampai dengan 0,30

- sedang untuk nilai indeks kemerataan 0,40 sampai dengan 0,60

- tinggi untuk nilai indeks kemerataan 0,70 sampai dengan 1,00

\section{HASIL DAN PEMBAHASAN}

Dari pengamatan yang telah dilakukan, didapatkan 7 Ordo burung yang terdiri dari 12 Famili dan 23 spesies burung. Total individu yang teramati adalah sebanyak 327 individu, 226 individu ditemukan di Pesisir Rempang dan 101 individu di Pesisir Tg. Piayu, seperti yang ditampilkan pada Tabel 1. 
Tabel 1. Jenis-Jenis Burung yang Terdapat di Lokasi Penelitian

\begin{tabular}{|c|c|c|c|c|c|}
\hline \multirow[b]{2}{*}{ Ordo/Famili/spesies ${ }^{\text {a }}$} & \multicolumn{2}{|c|}{ Status } & \multicolumn{2}{|c|}{ Lokasi Penelitian } & \multirow[b]{2}{*}{ Total } \\
\hline & $\mathrm{IUCN}^{\mathrm{b}}$ & $\mathbf{P P}^{\mathbf{c}}$ & Rempang & $\begin{array}{c}\text { Tg. } \\
\text { Piayu }\end{array}$ & \\
\hline \multicolumn{6}{|l|}{ Ordo: Accipitriformes; Famili: Accipitridae } \\
\hline 1. Haliastur indus (Boddaert, 1783) & $\mathrm{LC}$ & $\mathrm{L}$ & 21 & 4 & 25 \\
\hline \multicolumn{6}{|l|}{ Ordo: Charadriiformes; Famili: Scolopacidae } \\
\hline 2. Xenus cinereus (Guldenstadt, 1775) & $\mathrm{LC}$ & $\mathrm{TL}$ & 1 & 0 & 1 \\
\hline 3. Tringa totanus (Linnaeus, 1758) & $\mathrm{LC}$ & $\mathrm{TL}$ & 4 & 1 & 5 \\
\hline \multicolumn{6}{|l|}{ Ordo: Columbiformes; Famili: Columbidae } \\
\hline 4. Spilopelia chinensis (Scopoli, 1786) & $\mathrm{LC}$ & $\mathrm{TL}$ & 1 & 2 & 3 \\
\hline 5. Treron vernans (Linnaeus, 1771) & $\mathrm{LC}$ & $\mathrm{TL}$ & 7 & 9 & 16 \\
\hline \multicolumn{6}{|l|}{ Ordo: Coraciiformes; Famili: Alcedinidae } \\
\hline 6. Alcedo atthis (Linnaeus, 1758) & $\mathrm{LC}$ & $\mathrm{L}$ & 2 & 0 & 2 \\
\hline 7. Alcedo meninting Horsfield, 1821 & $\mathrm{LC}$ & $\mathrm{L}$ & 1 & 0 & 1 \\
\hline 8. Halcyon smyrnensis (Linnaeus, 1758) & $\mathrm{LC}$ & $\mathrm{L}$ & 3 & 5 & 8 \\
\hline 9. Pelargopsis capensis (Linnaeus, 1766) & $\mathrm{LC}$ & $\mathrm{L}$ & 3 & 1 & 4 \\
\hline 10. Todiramphus chloris (Boddaert, 1783) & $\mathrm{LC}$ & $\mathrm{L}$ & 3 & 2 & 5 \\
\hline \multicolumn{6}{|l|}{ Famili: Coraciidae } \\
\hline 11. Eurystomus Orientalis (Linnaeus, 1766) & $\mathrm{LC}$ & $\mathrm{TL}$ & 0 & 1 & 1 \\
\hline \multicolumn{6}{|l|}{ Famili: Meropidae } \\
\hline 12. Merops philippinus Linnaeus, 1766 & $\mathrm{LC}$ & $\mathrm{TL}$ & 5 & 5 & 10 \\
\hline \multicolumn{6}{|l|}{ Ordo: Gruiformes; Famili: Rallidae } \\
\hline 13. Amaurornis phoenicurus (Pennant, 1769) & $\mathrm{LC}$ & $\mathrm{TL}$ & 1 & 1 & 2 \\
\hline \multicolumn{6}{|l|}{ Ordo: Passeriformes; Famili: Corvidae } \\
\hline 14. Corvus enca (Horsfield, 1822) & $\mathrm{LC}$ & $\mathrm{TL}$ & 3 & 12 & 15 \\
\hline \multicolumn{6}{|l|}{ Famili: Dicaeidae } \\
\hline $\begin{array}{l}\text { 15. Dicaeum cruentatum (Linnaeus, 1758) } \\
\text { Famili: Ploceidae }\end{array}$ & $\mathrm{LC}$ & $\mathrm{TL}$ & 1 & 0 & 1 \\
\hline 16. Lonchura maja (Linnaeus, 1766) & $\mathrm{LC}$ & $\mathrm{TL}$ & 0 & 3 & 3 \\
\hline 17. Lonchura malacca (Linnaeus, 1766) & $\mathrm{LC}$ & $\mathrm{TL}$ & 4 & 0 & 4 \\
\hline \multicolumn{6}{|l|}{ Famili: Pycnonotidae } \\
\hline 18. Pycnonotus goiavier (Scopoli, 1786) & $\mathrm{LC}$ & $\mathrm{TL}$ & 2 & 12 & 14 \\
\hline \multicolumn{6}{|l|}{ Ordo: Pelecaniformes; Famili: Ardeidae } \\
\hline 19. Ardea cinerea Linnaeus, 1758 & $\mathrm{LC}$ & $\mathrm{L}$ & 10 & 4 & 14 \\
\hline 20. Ardea purpurea Linnaeus, 1766 & $\mathrm{LC}$ & $\mathrm{L}$ & 12 & 2 & 14 \\
\hline 21. Ardeola speciosa (Horsfield, 1821) & $\mathrm{LC}$ & $\mathrm{L}$ & 2 & 0 & 2 \\
\hline 22. Egretta alba Linnaeus, 1758 & $\mathrm{LC}$ & $\mathrm{L}$ & 94 & 31 & 125 \\
\hline 23. Egretta garzetta (Linnaeus, 1766) & $\mathrm{LC}$ & $\mathrm{L}$ & 46 & 6 & 52 \\
\hline Total & & & 226 & 101 & 327 \\
\hline
\end{tabular}


Keterangan: a Tata nama berdasarkan MacKinnon (1992) dan IUCN 2016. ${ }^{\mathrm{b}}$ Status Perlindungan berdasarkan IUCN Redlist tahun 2016; LC: Least Concern. ${ }^{\mathrm{c}}$ Status perlindungan berdasarkan Peratutan Pemerintah republik Indonesia No. 7 tahun 1999; L: dilindungi; TL: Tidak diliindungi.

Dari 12 famili yang ditemukan, famili dengan jumlah terbanyak adalah Alcedinidae dan Ardeidae masing-masing sebanyak 5 jenis dan spesies yang termasuk ke dalam kedua famili tersebut merupakan burung yang dilindungi menurut PP No 7 tahun 1999. Famili Alcedinidae adalah kelompok burung pemakan serangga dan vertebrata kecil, termasuk ikan. Memiliki ciriciri tubuh berwarna terang, kaki dan ekor pendek, kepala besar, paruh panjang dan kuat. Burung yang termasuk ke dalam famili Alcedinidae ditemukan sebanyak 20 individu. Famili Ardeidae adalah kelompok burung berkaki panjang, leher panjang, paruh panjang lurus yang digunakan untuk mencotok ikan, vertebrata kecil dan invertebrata (MacKinnon, et.al., 1992). Famili Ardeidae adalah famili dengan jumlah individu terbanyak dari semua famili yang ditemukan, yaitu sebanyak 207 individu. Banyaknya jumlah individu dari Famili Ardeidae yang teramati disebabkan karena pada waktu penelitian bertepatan dengan jadwal kunjungan migrasi burung, dimana sebagian besar spesies dari Ardeidae adalah kelompok burung migran. Indonesia merupakan tempat persinggahan antara bagi burung yang melakukan migrasi dari belahan bumi utara menuju belahan bumi selatan (September-Maret) (Noor, 2003).

Semua jenis yang teramati termasuk kedalam status perlindungan Least Concern (LC; berisiko rendah) menurut IUCN Versi 3.1 (2001). Kategori LC diberikan untuk spesies yang telah dievaluasi namun tidak masuk ke dalam kategori manapun. Sementara menurut PP No 7 tahun 1999, 11 spesies yang ditemukan termasuk burung yang dilindungi dan 12 spesies tidak dilindungi.

\section{Diversitas dan Kemerataan Spesies Burung}

Nilai indeks diversitas dan kemerataan spesies burung pada kawasan lahan basah kota Batam dapat dilihat pada Tabel berikut.

Tabel 2. Diversitas dan Kemerataan Spesies Burung di lahan basah kota Batam

\begin{tabular}{lcccc}
\hline \multicolumn{1}{c}{ Lokasi } & \multirow{2}{*}{ Spesies } & Individu & $\begin{array}{c}\text { Indeks Diversitas } \\
\left(\mathrm{H}^{\prime}\right)\end{array}$ & $\begin{array}{c}\text { Indeks Kemerataan } \\
\left(\mathrm{J}^{\prime}\right)\end{array}$ \\
\hline Monggak & 21 & 226 & 2.01 & 0.66 \\
Tg.Piayu & 17 & 101 & 2.33 & 0.82 \\
\hline Kota Batam & 23 & 327 & 2.23 & 0.71 \\
\hline
\end{tabular}


Nilai indeks Diversitas burung di kedua lokasi tergolong sedang yaitu masing-masing 2,01 dan 2,33. Nilai indeks kemerataan burung di Monggak tergolong sedang yaitu 0,66 dan di Tg. Piayu tergolong tinggi yaitu 0,82 .

\section{Deskripsi Jenis Burung}

1. Haliastur indus (Boddaert, 1783)

Nama Indonesia: Elang Bondol

Nama Umum: Brahminy Kite

Berukuran agak besar, bulu berwarna putih dan coklat pirang, paruh berwarna kekuningan, kokoh dan kuat. Sering ditemukan terbang di atas perairan dan bertengger di pohon yang tinggi.

2. Xenus cinereus (Guldenstadt, 1775)

Nama Indonesia: Trinil Bedaran

Nama Umum: Terek Sandpiper

Berukuran sedang, berwarna abu-abu, paruh panjang dan sedikit melengkung ke atas.

Bagian atas abu-abu, alis putih, bulu primer hitam mencolok. Bagian bawah putih, kaki relatif pendek. Pinggir belakang yang putih dan sempit pada sayap terlihat mencolok pada waktu terbang. Menurut MacKinnon (1994) termasuk burung migran. Berbiak di erasia utara, tetapi bermigrasi ke selatan pada musim dingin sejauh Australia dan Selandia Baru.

3. Tringa totanus (Linnaeus, 1758)

Nama Indonesia: Trinil Kaki Merah

Nama Umum: Common Redshank

Berukuran sedang. Kaki jingga kemerahan, paruh panjang runcing pada bagian pangkal berwarna kemerahan dan bagian lainnya hitam. Bagian atas abu-abu kecoklatan, bagian bawah putih, dada bercoretan coklat. Ditemukan berdiri di tepi perairan.

4. Spilopelia chinensis (Scopoli, 1786)

Nama Indonesia: Tekukur Biasa

Nama Umum: Spotted-Dove 
Berukuran sedang, berwarna coklat kemerahkambuan. Ekor tampak panjang. Bulu ekor terluar memiliki tepi putih tebal. Bulu sayap lebih gelap daripada bulu tubuh. Terdapat garis-garis hitam khas pada sisi-sisi leher, berbintik-bintih putih halus

5. Treron vernans (Linnaeus, 1771)

Nama Indonesia: Punai Gading

Nama Umum: Pink-necked Green-Pigeon

Berukuran agak kecil (untuk ukuran famili Columbidae), berwarna hijau. Jantan: kepala abu-abu kebiruan, sisi leher, tengkuk bawah dan garis melintang pada dada berwarna merah jambu. Dada bagian bawah jingga, perut hijau dengan bagian bawah kuning, sisisisi rusuk dan paha bertepi putih, penutup bagian bawah ekor coklat kemerahan, punggung hijau, bulu penutup ekor atas perunggu. Sayap gelap dengan tepi kuning yang kontras pada bulu-bulu penutup sayap besar. Ekor abu-abu dengan garis hitam pada bagan sub terminal dan tepi abu-abu pucat. Betina: Hijau tanpa warna merah jambu, abuabu dan jingga seperti pada jantan. Selalu ditemukan dalam berkelompok dan bertenger di puncak pohon yang tinggi.

6. Alcedo atthis (Linnaeus, 1758)

Nama Indonesia: Raja-udang Erasia

Nama Umum: Common Kingfisher

Berukuran kecil, berwarna biru menyala dan merah bata. Tubuh bagian dorsal bersinar biru kehijauan pucat, tubuh bagian ventral jingga merah bata dengan dagu putih. Terdapat bintik putih pada sisi leher serta setrip jingga yang melewati mata yang menutupi penutup telinga yang mencolok. Sering ditemukan bertengger sendirian di ranting pohon di atas perairan.

7. Alcedo meninting Horsfield, 1821

Nama Indonesia: Raja-udang Meninting

Nama Umum: Blue-eared Kingfisher

Berukuran kecil, dorsal biru terang/ metalik, lebih gelap daripada Alcedo atthis. Tubuh bagian ventral berwarna merah jingga terang, penutup telinga biru mencolok. Sering ditemukan bertengger di atas perairan.

8. Halcyon smyrnensis (Linnaeus, 1758) 
Nama Indonesia: Cekakak Belukar

Nama Umum: White-throated Kingfisher

Berukuran agak besar, berwarna biru dan coklat. Dagu, tenggorokan dan dada putih, kepala, leher dan sisa tubuh bagian bawah berwarna coklat. Mantel sayap dan ekor berwarna biru terang berkilau. Penutup sayap atas dan ujung sayap coklat tua. Sering ditemukan bertengger di atas perairan.

9. Pelargopsis capensis (Linnaeus, 1766)

Nama Indonesia: Pekaka Emas

Nama Umum: Stork-billed Kingfisher

Berukuran sangat besar (untuk family Alcedinidae). Punggung biru dengan paruh merah mencolok. Mahkota, sisi muka, dan tengkuk coklat abu-abu. Tubuh bagian bawah berwarna jingga kemerahjambuan. Sering ditemukan bertengger diatas ranting pohon yang agak tinggi.

10. Todiramphus chloris (Boddaert, 1783)

Nama Indonesia: Cekakak Sungai

Nama Umum: Collared Kingfisher

Berukuran sedang, berwarna biru dan putih. Mahkota, sayap, punggung dan ekor biru kehijauan berkilau terang. Ada setrip hitam melewati mata. Kerah dan tubuh bagian bawah berwarna putih bersih. Sering ditemukan bertengger di atas perairan.

11. Eurystomus Orientalis (Linnaeus, 1766)

Nama Indonesia: Tiong-Lampu Biasa

Nama Umum: Dollarbird

Berukuran sedang, berwarna gelap. Paruh merah lebar. Warna bulu keseluruhan adalah abu-abu kebiruan gelap, kecuali kerongkongan biru terang.

12. Merops philippinus Linnaeus, 1766

Nama Indonesia: Kirik-kirik Laut

Nama Umum: Blue-tailed Bee-eater

Berukuran sedang, memiliki ekor panjang dengan pita yang lebih panjang pada bagian tengahnya

13. Amaurornis phoenicurus (Pennant, 1769) 
Nama Indonesia: Kareo Padi

Nama Umum: White-breasted Waterhen

Berukuran besar, berwarna abu-abu dan putih mencolok. Mahkota dan tubuh bagian atas abu-abu, muka, dahi, dada, dan bagian atas perut putih bagian bawah peru dan ekor bagian bawah merah karat. Paruh kehijauan dengan pangkal merah dan kaki kuning.

14. Corvus enca (Horsfield, 1822)

Nama Indonesia: Gagak Hutan

Nama Umum: Slender-billed Crow

Berukuran besar. Tubuh secara keseluruhan berwarna hitam. Kepakan sayap pendek. Paruh dan kaki hitam.

15. Dicaeum cruentatum (Linnaeus, 1758)

Nama Indonesia: Cabai Merah

Nama Umum: Scarlet-backed Flower Pepecker

Berukuran kecil berwarna hitam dan merah. Jantan: mahkota, punggung dan tunggir merah padam, sayap, sisi kepala, dan ekor hitam. Tubuh bagian bawah putih dengan sisi tubuh abu-abu.

16. Lonchura maja (Linnaeus, 1766)

Nama Indonesia: Bondol Haji

Nama Umum: White-headed Munia

Berukuran agak kecil, berwarna coklat dengan kepala putih, seluruh kepala dan tenggorokan putih. Biasa ditemukan berkelompok di padang ilalang dan tempat terbuka.

17. Lonchura malacca (Linnaeus, 1766)

Nama Indonesia: Bondol Rawa

Nama Umum: Black-headed Munia

Berukuran agak kecil, berwarna coklat berangan dengan kepala hitam. Biasa ditemukan berkelompok hinggap di rumput-rumput yang agak tinggi. Biasa hadir bersamaan dengan Lonchura maja.

18. Pycnonotus goiavier (Scopoli, 1786)

Nama Indonesia: Merbah Cerukcuk

Nama Umum: Yellow-vented Bulbul 
Berukuran sedang, berwarna coklat dan putih dengan tunggir kuning khas. Mahkota coklat gelap, alis putih, kekang hitam. Tubuh bagian atas coklat. Tenggorokan, dada, dan perut putih dengan coretan coklat pucat pada sisi lambung. Paruh hitam, kaki abu-abu kemerahjambuan.

19. Ardea cinerea Linnaeus, 1758

Nama Indonesia: Cangak Abu

Nama Umum: Grey Heron

Berukuran besar, berwarna putih, abu-abu dan hitam. Kaki dan leher panjang, paruh besar, panjang dan kuat. Sering ditemukan di sekitar tambak ikan dan bertengger di atas tumbuhan mangrove yang rendah.

20. Ardea purpurea Linnaeus, 1766

Nama Indonesia: Cangak Merah

Nama Umum: Purple Heron

Berukuran besar, berwarna abu-abu, coklat berangan dan hitam. Topi hitam dengan jambul menjuntai. Terdapat setrip hitam menurun sepanjang leher yang merah-karat khas. Punggung dan penutup sayap abu-abu, bulu terbang hitam, dan bulu lainnya coklat kemerahan.

21. Ardeola speciosa (Horsfield, 1821)

Nama Indonesia: Blekok Sawah

Nama Inggris: Javan Pond Heron

Berukuran kecil (untuk ukuran Famili Ardeidae). Sayap putih, coklat bercoret-coret. Dada putih bercoret, kepala dan punggung nyaris hitam. Tubuh bagian bawah putih. Leher bisa dipanjangkan sampai dua kali lipat. Ditemukan bertengger di puncak pohon mangrove dan di ranting pohon yang cukup tinggi

22. Egretta alba Linnaeus, 1758

Nama Indonesia: Kuntul Besar

Nama Umum: Great Egret

Berukuran besar,jauh lebih besar daripada kuntul putih lain. Bulu putih, paruh besar panjang dan leher bersimpul khas. Kaki dan tungkai hitam.

23. Egretta garzetta (Linnaeus, 1766) 
Nama Indonesia: Kuntul kecil

Nama Umum: Little Egret

Berkuran sedang, berbulu putih, paruh dan kaki hitam. Ditemukan sendirian di dekat perairan.

\section{KESIMPULAN}

Terdapat 327 individu burung yang teramati di lokasi penelitian yang terdiri dari 7 Ordo, 12 famili dan 23 spesies. Nilai indeks diversitas burung di kedua lokasi tergolong sedang yaitu masing-masing 2,01 dan 2,33. Nilai indeks kemerataan burung di Monggak tergolong sedang yaitu 0,66 dan di Tg. Piayu tergolong tinggi yaitu 0,82 .

\section{REFERENSI}

Bibby, CJ, Burgess, ND., Hill, DA. \& Mustoe, SH. 2000. Bird Census Techniques. 2nd Ed. Academic Press. Tokyo.

Djuwantono, S.Pudyatmoko, A.Setiawan, DW.Purnomo, S.Nurvianto, FY. Laksono, YCW. Kusuma. 2013. Studi keanekaragaman jenis burung terkait dengan suksesi ekologi di Suaka Margasatwa Paliyan da Hutan Pendidikan Wanagama, Kabupaten Gunung Kidul. http://lib.ugm.ac.id/digitasi/upload/2695_MU.11100001.pdf. Diakses 10 Oktober 2016.

Howes, J., D. Bakewell, dan Y. Rusila-Noor. 2003. Panduan Studi Burung Pantai. Wetlands International-Indonesia Programme. Bogor.

MacKinnon, J., K. Phillips dan B. van Ballen. 1994. Burung-burung di Sumatera, Jawa, Bali dan Kalimantan (Termasuk Sabah, Sarawak dan Brunei Darussalam) [LIPI-Seri Panduan Lapangan]. Puslitbang Biologi-LIPI. Bogor.

Primack, J.B.; J. Supriatna; M. Indrawa \& P. Kramadibrata. 1998. Biologi Konservasi. Yayasan Obor Indonesia. Jakarta. Rose, P.M. and D.A. Scott. 1994. Waterfowl Population Estimates. IWRB, Publication No.29. Slimbridge. U.K.: IWRB.

Rusila-Noor, Y., M. Khazali, and I.N.N Suryadiputra. 1999. Panduan Pengenalan Mangrove di Indonesia. PKA \& Wetlands International-Indonesia Programme. Bogor.

Wechsler, D. \& B.K. Wheeler. 2012. BirdCast: Why You Should Care: Birds as Bioindicators. http://www.birdsource.org. Diakses 12 Oktober 2016.

Junardi dan Elfidasari, D. 2006. Keragaman Burung Air di Kawasan Hutan Mangrove Peniti, Kabupaten Pontianak. Biodiversitas Vol 7 No. 1. Hal 63-66 


\section{Lampiran}

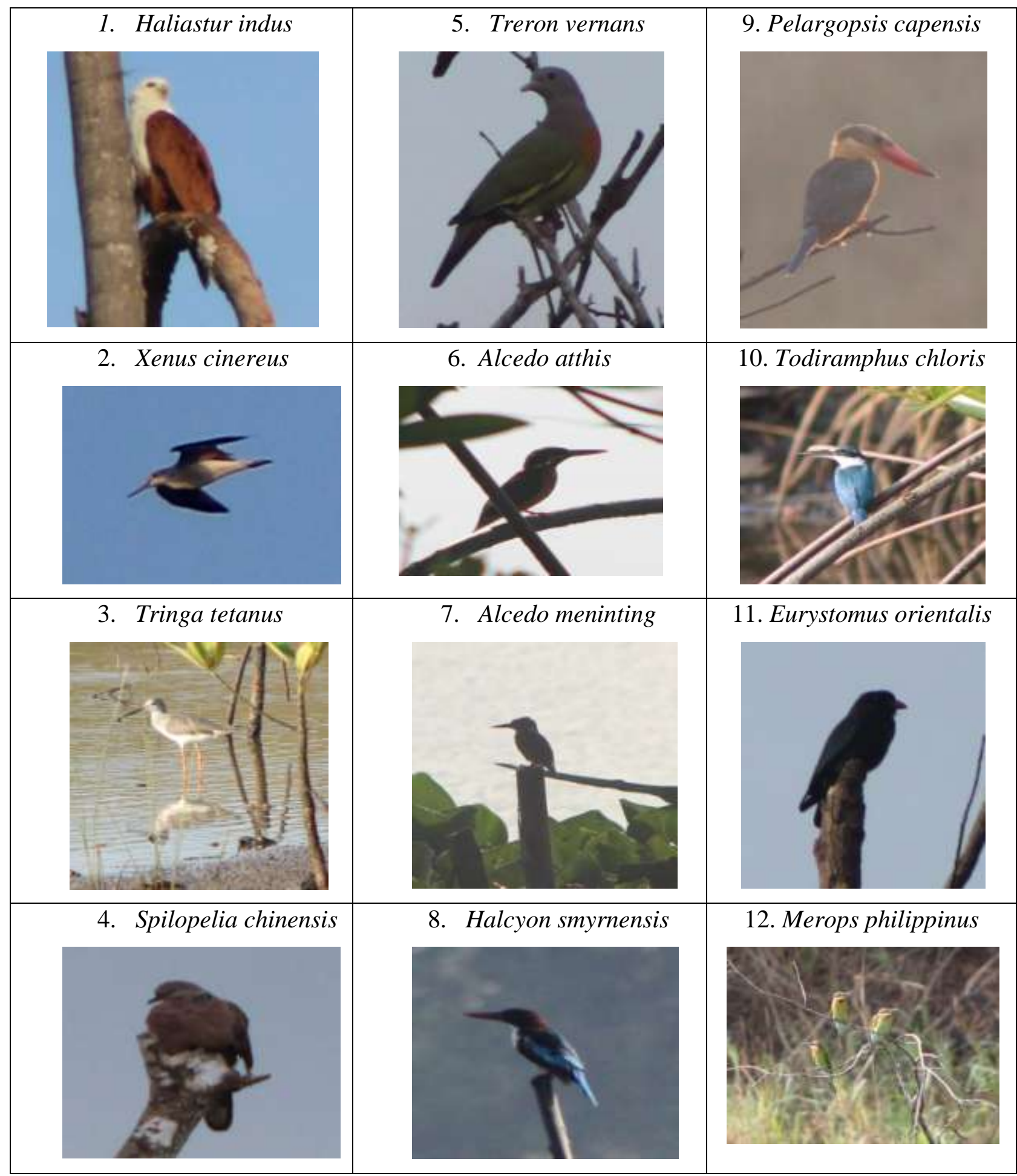


Fauziah Syamsi : Keanekaragaman Burung....

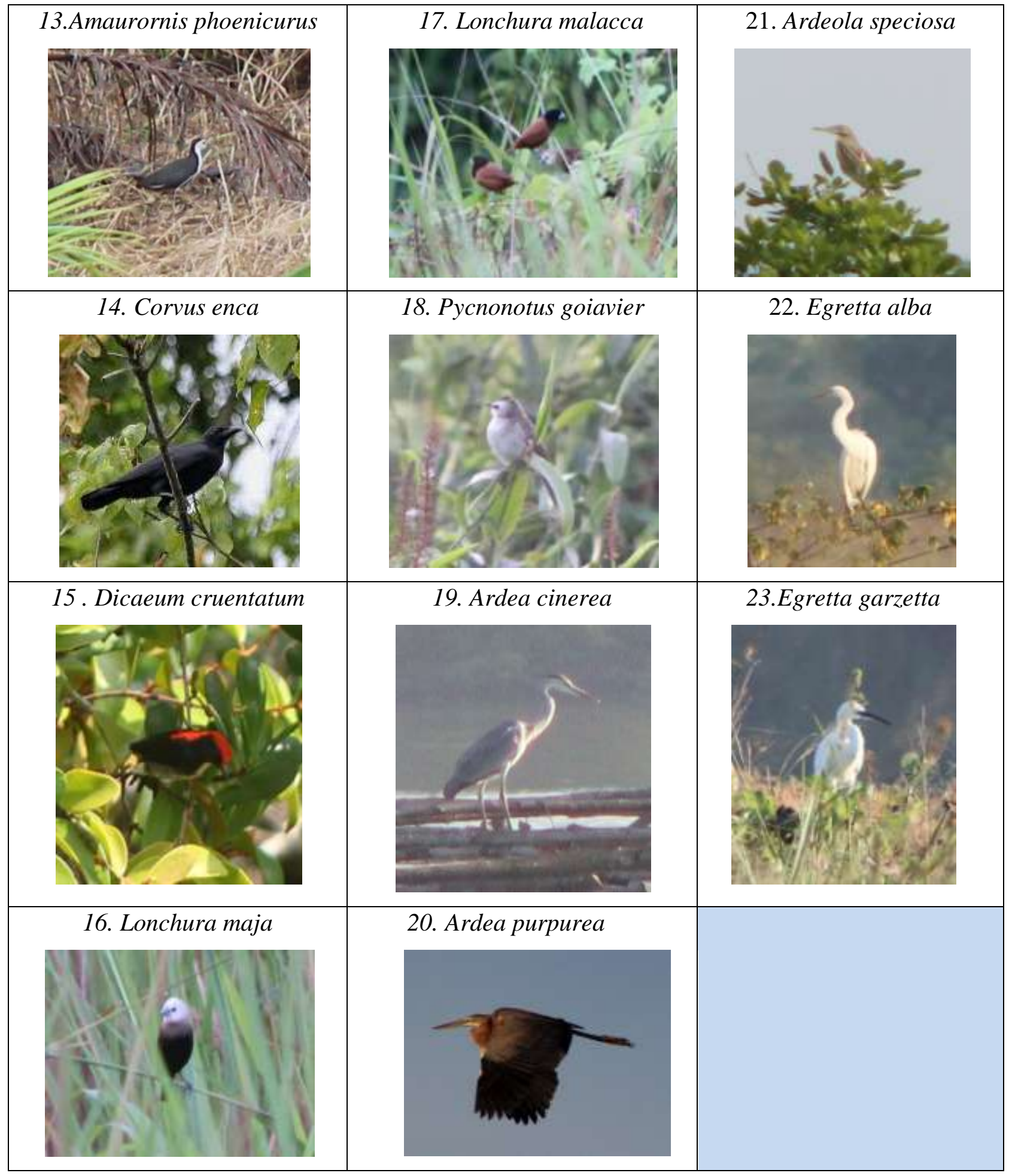

